\title{
Intracellular distribution of antitumor Ru (II) compounds: The lysosome and the lysosomal enzymes as targets for anticancer metal-based drugs
}

\author{
F. Marques*, L. Corte-Real*, A.P. Alves de Matos**, I. Alho***, T.S. Morais****, A.I. Tomaz****, M.H. \\ Garcia****, M.P. Bicho*** \\ *Unidade Ciências Químicas e Radiofarmacêuticas, Instituto Superior Técnico, Polo de Loures-Campus \\ Tecnológico e Nuclear, EN 10, 2685-953 Sacavém, Portugal \\ **Anatomia Patológica, Centro Hospitalar de Lisboa Central - HCC, Rua da Beneficência 8, 1069-166 Lisboa, \\ Portugal; Centro de Estudos do Ambiente e do Mar (CESAM/FCUL) - Faculdade de Ciências da Universidade de \\ Lisboa and Centro de Investigação Interdisciplinar Egas Moniz (CiiEM), Quinta da Granja , Monte de Caparica, 2829- \\ 511 Caparica, Portugal \\ ***Laboratório de Genética, Faculdade de Medicina de Lisboa, Avª Prof. Egas Moniz, 1649-028 Lisboa, \\ Portugal \\ ****Centro de Ciências Moleculares e Materiais, Faculdade de Ciências da Universidade de Lisboa, Campo \\ Grande, 1149-016 Lisboa, Portugal
}

The therapeutic usefulness of anticancer agents relies on their ability to kill cancer cells while sparing normal cells and tissues. Ruthenium complexes hold great potential as suitable alternative drugs to the current cisplatin in the treatment of cancer. Our approach in this field has been the study of organoruthenium complexes, $\left[\mathrm{Ru} \mathrm{u}^{\mathrm{II}}\left(\eta^{5}-\right.\right.$ $\mathrm{Cp})]$ family, namely $\left[\mathrm{Ru}^{\mathrm{II}}\left(\eta^{5}-\mathrm{Cp}\right)(\text { bipy })\left(\mathrm{PPh}_{3}\right)\right]^{+}\left(\mathrm{PPh}_{3}=\right.$ triphenylphosphine; bipy $=2,2^{\prime}$-bipyridine $)$, TM34 $[3,4]$. This compound was tested for antitumor activity against tumor cells representative of human cancer diseases. A large spectrum of activity was found, largely surpassing cisplatin in efficacy (Fig 1).

How a drug distributes and localizes within cells is of fundamental importance as the drug must concentrate in the compartment that houses its target(s) [5]. The importance of cellular enzymes on the effects of anticancer drugs for which multiple biological pathways have been proposed led us to address the involvement of the lysosomes and lysosomal enzymes (AcPases) in the mechanism of cell death.

The cytotoxicity of TM34 was tested using the MTT assay. TM34 cellular distribution was measured by ICPMS. The effect of TM34 on the activity of acid phosphatase (AcPase) was evaluated by the hydrolysis of $p$ nitrophenyl phosphate to $p$-nitrophenol. AcPase localization was investigated by TEM using the Record and Griffing (1988) cerium-based method [6].

Results showed that the sensitivity of AcPase assay is higher in comparison to cell proliferation assays based on the reduction of tetrazolium salts (MTT) (Fig 2). From TEM images AcPase reaction product appears as dark electron dense deposits in the lysosomes and dictiosomes. After $3 \mathrm{~h}$ treatment TM34 provokes disruption and vesiculation of the Golgi apparatus, although some reaction product is present in the lysosomes (Fig 2).

The lysosome could be considered a possible target for TM34. Morphological evidence was observed for the participation of the Golgi apparatus in the vesiculation induced by the compound.

1. Hartinger C.G. et al., Chemistry and Biodiversity, 5:2140, 2008.

2. Jakupec M.A. et al., Dalton Trans., 14:183, 2008.

3. Moreno V. et al., J. Inorg. Biochem., 105:241, 2011.

4. Tomaz A.I. et al., J. Inorg. Biochem., 117:261, 2012.

5. Ndolo R.A. et al., Mol. Cell. Pharmacol,, 2:131, 2010.

6. Balcerczyk A. et al., Biochem. Pharmacol., 69:1263, 2005. 

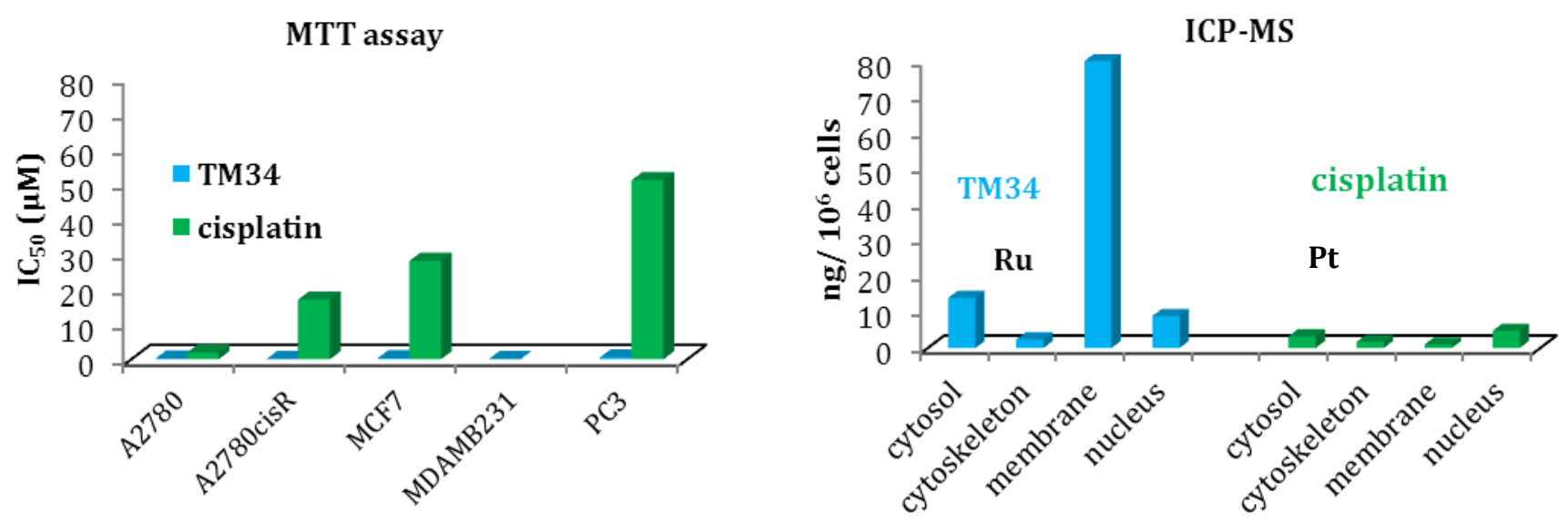

Fig. 1 - Cytotoxic activity of TM34 against several human tumor cells: A2780 and A2780cisR (ovarian cancer, cisplatin sensitive/ resistant pair), MCF7 and MDAMB231 (breast cancer) and PC3 (prostate cancer) and cellular distribution of Ru (TM34) in A2780 cells by ICP-MS. Cisplatin was used as reference compound.

A

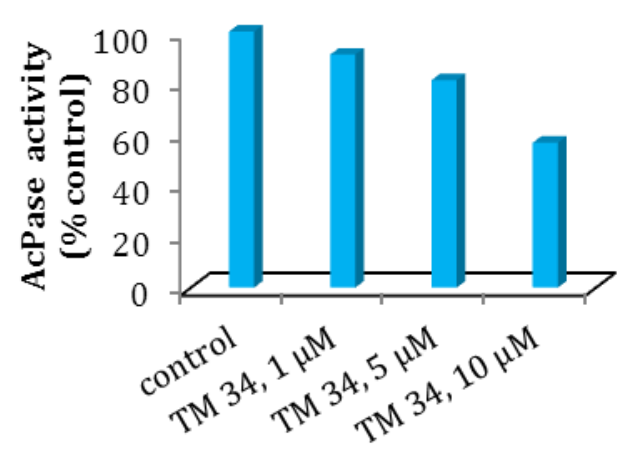

MTT assay

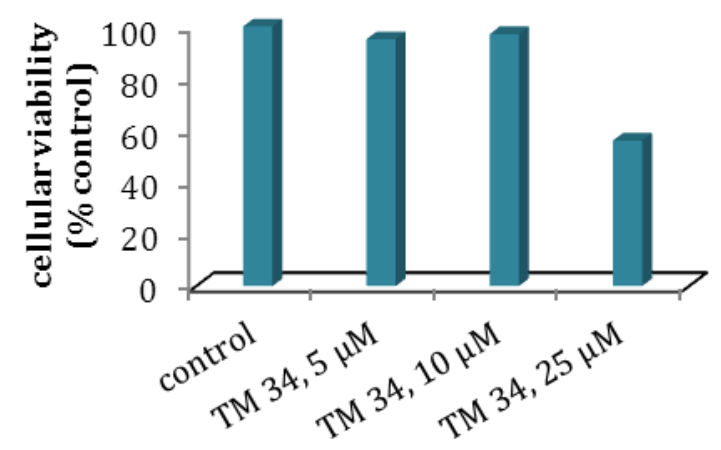

$\mathbf{B}$
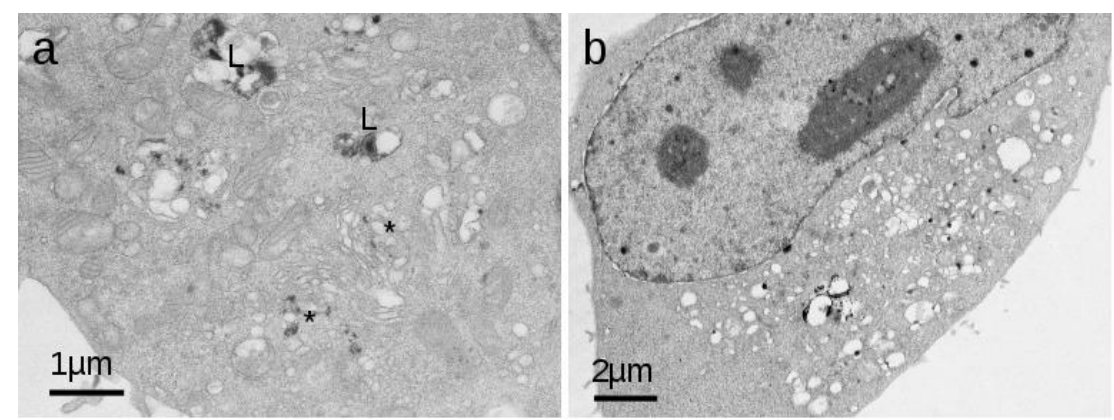

Fig 2 - Acid Phosphatase activity (A) and TEM images showing enzyme localization (B): a) Control, Cytochemistry of untreated MDAMB231 cells. Reaction product is found in lysosomes (L) and in the transGolgi region of dictiosomes (*); b) Cytochemistry of MDAMB231 cells after $3 \mathrm{~h}$ treatment with TM34. Disruption and vesiculation of the Golgi apparatus. Some reaction product can be found in lysosomes (L), possibly formed before treatment.

Supported by the Fundação para a Ciência e Tecnologia (FCT): PTDC/QUI-QUI/101187/2008. 